\title{
Backs in the Future: A Journey Through the Spinal Landscape
}

\author{
Chris J. Main ${ }^{1}$
}

Published online: 18 July 2020

(c) Springer Science+Business Media, LLC, part of Springer Nature 2020

\section{Introduction}

The purpose of this article is to offer a personal perspective on my involvement with the assessment and management of low back pain (LBP) over four + decades as both a clinician and a researcher. The story begins with a biomedical (orthopaedic) perspective on which is built the psychosocial components leading to the development of the biopsychosocial model of LBP; moves to the establishment of a tertiary pain management programme and the development of secondary prevention; and concludes with the description of psychologically informed practice (PiP) as a way of establishing guided self-management. On the journey, consideration will be given to the development of assessment, screening and targeting treatment in both clinical and occupational settings. It concludes with reflections at the levels of individual management, organisations and healthlsocial policy.

I have struggled with a number of questions over the years, which can serve as a road-map of the "drivers" underpinning the LBP story. I began in the orthopedic world with a number of questions about LBP, such as:

\section{Why do People with "Apparently" the Same Physical Findings Differ in how Disabled They Become?}

Answering that question proved extraordinarily difficult since the measurement tools available to measure LBP and its effects were poorly constructed and inadequately validated. We had to construct our own.

\section{Can we Explain Pain-Associated Disability in Terms of Psychological Factors?}

Psychologists, steeped in psychopathology, purported to explain differences in symptom development from

Chris J. Main

profcmain@gmail.com

1 Keele University, Keele, UK "psycho-anatomical X-rays" using cumbersome psychometric tests such as the Minnesota Multiphasic Personality Inventory (MMPI), which contained virtually no questions about pain or pain coping strategies. We set about assessing the relationship of a range of tests with pain and level of disability and we found that fairly simple assessments of somatic awareness, depressive symptoms and behavioral signs and symptoms explained a significant amount of variance in disability, even after controlling for physical findings. This enabled the construction of the Glasgow Illness Model [1]. (A specific focus on the assessment of cognitive factors in pain had not yet been developed).

\section{Can Health Care Providers do Anything to Help People with High Levels of Chronic Pain and Disability?}

We established an inter-disciplinary pain management programme in Salford, allowing us also to explore some of the psychophysiological features of LBP and the role of fear [2] for which we developed the Fear Avoidance Beliefs Questionnaire (FABQ) [3]. We also developed a brief occupationally focussed approach for treating unemployed LBP sufferers in receipt of time loss benefits [4].

\section{Can we Identify People Likely to Develop Chronic Pain and "Unnecessary" Levels of Pain-Associated Distress and Disability?}

As an evidence-informed model of psychosocial risk, the Yellow Flags framework [5] prompted a sudden and unpredicted international interest, probably because it addressed secondary prevention for which clinical guidelines were appearing. During the next decade, we developed the Keele STarT Back Screening Tool from studies in Primary Care [6]. 


\section{Can we Stop People from Developing Chronic LBP and Pain-Associated Disability?}

My move to the Primary Care Centre at Keele University offered me the opportunity to draw on the expertise of the research team established by Peter Croft. We reconfigured the Salford Pain Management Program (PMP) into a shorter programme delivered primarily by specially trained physiotherapists and demonstrated the value of a stratified (screening and targeting) approach in Primary Care [7]. So, let us return to the beginning of the story.

The Journey.

\section{University of Glasgow \& Orthopaedics}

As part of training as a clinical psychologist in Edinburgh (1974), I completed a thesis looking at the prediction of outcome of surgery for peptic ulcer and became interested in people's perception of physiological activity. After qualification, I had access to a temperature and sound controlled lab at the Royal Edinburgh Hospital and began to investigate the psychophysiology of anxiety using a 16-channel polygraph. In 1976, on moving to a more senior post at Gartnavel Royal Hospital I registered for a Ph.D., making use of a somewhat elderly polygraph. It was kept functioning by an ex-naval electronics technician working as a hospital electrician and he was delighted to have someone use his "pride and joy". His fondness for whisky had led previously to a parting with the Navy and unfortunately history repeated itself and he lost his job at the hospital. No-one else could persuade the polygraph to function properly and I had no money to buy a new machine or hire someone to maintain it, so my Ph.D. appeared to be doomed. Fortuitously, an Orthopaedic Surgeon called Gordon Waddell (GW) thought his patients might benefit from a 4-session multidisciplinary back school, which he had observed in Toronto. Since I was the only one of the clinical psychologists who had an interest in general medicine, I was introduced to GW. I knew nothing about LBP, so I asked if I might sit in a few of his clinics.

I discovered that GW had the most systematic organisation of clinical data and I explored the possibility of asking his patients to complete questionnaires which I discovered were in vogue in North America. I was anxious about the reliability and validity of some of the measures, so we designed and tested a comprehensive assessment of the physical and psychological features of LBP. The battery was subsequently completed by hundreds of patients. Evaluating the assessment tools enabled us to prune the initial data set and investigate influences on the level of pain-associated disability reported by the patients. It was published initially as the Glasgow Illness Model in 1984 [1] and was further refined and embedded by GW in the biopsychosocial model of pain and disability in 1987 [8].

We had trawled the medical literature for signs and symptoms considered of relevance in assessing LBP. Getting three surgeons independently to rate the same patients to assess inter-rater reliability of each of the signs and symptoms was a logistical nightmare, but had its humorous moments. We conducted a survey of 22 orthopaedic and neurosurgeons to rate what issues were typical of patients with LBP they saw in their clinics. One of the recommended items was "Flattery or seductiveness to the doctor", which provoked some testy replies such as "What sort of clinic do you think we are running here?".

We found that only a minority of the signs were reliable and some of them were relatively rare. The published levels of agreement were explained almost entirely by agreement on the absence of the signs rather than their occurrence. Our revised assessment of physical examination was published in 1982 and generated much interest [9]. It was used in our later model building of patient-reported functional disability. For about 4 years we were swamped with data, analysed via punch-cards that we had to program on a main frame computer that ran overnight, but stopped every time it found an error in our programming.

The 1980s were characterised by data analyses, talks, and increasing travel, with much focus on the assessment of pain and pain behavior. There were two "behavioural" initiatives which developed in the early 1980s since the influence of Bill Fordyce had gradually spread. In 1982, Frank Keefe and colleagues developed a behavioral observation test for LBP comprising a 10 min sequence of movements (eg sitting, standing, walking etc.) that were videotaped and rated [10]. It was essentially a research tool and we later used it as a measure of change in our pain management programme (PMP). We sent the pre- and post-videos to Frank for independent blinded evaluation. The weeks went by with, uncharacteristically, no response from Frank. It turned out finally they had been held up in U.S. Customs as potentially pornographic. The second initiative was the non-organic signs (NOS) [11]. These were later described as 'inappropriate' signs and eventually "behavioural responses to examination". Unfortunately, they became widely misused as indicators of malingering until we formally re-emphasised their appropriate interpretation and use in 1998 [12] as probable indicators of apprehension, particularly about physical examination. At the time they were developed, the importance of cognitive and behavioral coping strategies had not yet become apparent.

These two examples illustrate the "illusion of objectivity". Although the term "subjective" is often used with 
distaste, as if it were inherently second rate or untrustworthy, most pain assessment is based on subjective report. Pain behaviour is descriptive, and often valuable. However, it is easily influenced by the prejudice of the observer and is often over-interpreted. Explanation and interpretation need corroboration with additional information. As a final aside, I will mention a set of slides which I frequently use in teaching. They illustrate a lady who consulted us in the Pain Clinic with LBP, apparently unable to walk for 4 years. She arrived on an ambulance gurney, walked effortlessly across to the examination couch, but showed none of the usual physical signs such as loss of lordosis, limited straight leg raise, etc. The slides then show the ambulance which brought her and the driver, who was her husband. It turned out he had bought the ambulance for her, customised it with cooking facilities, toilet etc. and he drives her round the UK from clinic to clinic, consulting various back specialists. I showed the slides at a workshop and asked for opinions about her LBP and invalidity. An anaesthetist shot to her feet, red in the face, over-breathing and almost shouted "I hate patients like this". Other clinicians were more sympathetic and talked about further assessment, and the possibility of phased re-activation etc. Everyone had seen the same set of slides, yet the clinicians' interpretations were wildly different.

A landmark event for me was the award of a 1982 Winston Churchill Travelling Fellowship to North America to study new approaches to the treatment of pain. GW and I were accustomed at $5 \mathrm{pm}$ on Fridays to have a couple of beers before heading home. On the table was an application form for a Winston Churchill Memorial Trust (WCMT) scholarship. One of the categories was "New medical approaches to the treatment of pain".GW thought that my work on LBP might be relevant and so I hastily completed the form (as if entering a car competition) and sent it off thinking no more about it. Three weeks later to my astonishment I was invited for interview to Kensington Palace Gate (adjoining Buckingham Palace) to be interviewed by two members of the House of Lords (Lord Flowers, Head of the Science Research Council and Baroness Masham, Minister for the Disabled), and chaired by Sir George Pinker, the Queen's Surgeon and Gynaecologist (whom it had been announced that morning was to deliver Lady Diana's first child (Prince William, born in June 1982). Amazingly, I obtained a scholarship which enabled me to travel around the USA and Canada for 7 weeks visiting renowned pain clinics, learning about pain management programs and establishing a personal link with many of the leaders in the field. These included Bill Fordyce, John Loeser, Ken Craig, Dennis Turk, and Frank Keefe. I recall their courtesy and kindness with great affection.

\section{University of Manchester \& Tertiary PMP}

In 1982, I was recruited to develop a PMP in the Manchester and Salford Pain Centre, with an academic attachment to the Rheumatic Diseases Centre headed by Prof Malcolm Jayson (rheumatologist) at the University of Manchester. Over the next decade Chris Spanswick (pain anaesthetist) and myself, with support of many others, established the first interdisciplinary PMP specifically for LBP in the UK. This was a 3-week, day-patient programme which for a while served as a prototype of inter-disciplinary pain management in the UK and parts of Europe.

The next decade comprised progressive expansion and refinement of the approach, with the establishment of training workshops often via the British Pain Society (which had become multidisciplinary in 1987) and at world congresses of the International Association for the Study of Pain (which I have attended religiously). The PMP was developed still further through the 1990s with the arrival of Paul Watson (PW), a clinical \& research physiotherapist. We described the interdisciplinary PMP approach in the 1st edition of our textbook on Interdisciplinary Pain Management, published in 2000 [13], in which we acknowledged a huge debt to Bill Fordyce in particular for advice, guidance and support. His influence has been immense and I am pleased that a number of us recently managed to republish his original 1976 textbook with additional commentaries [14]. The Salford Team was privileged in turn to support the development of other PMPs in the UK, Europe and Australasia. An important part of the Salford PMP was learning from group sessions with patients who had become physically and psychologically disabled, often as a consequence of multiple and at times unnecessary surgery. As time went on, the need to try to prevent some of this iatrogenic (treatment-induced) disability became increasingly apparent. The manual we had written for patients underpinned Living with Back Pain [15] and the aforementioned textbook extensively revised in 2008 targeted health-care professionals. The decade was characterised by talks at medical meetings and congresses, often as the only psychologist, often on the same bill as my colleague and friend Peter Croft as the only epidemiologist.

\section{Primary \& Secondary Prevention-Yellow Flags}

In 1997, I had been awarded a Personal Chair in Rheumatic Diseases and took an opportunity in 2002 to focus more of my efforts on teaching, research and writing. I 
moved to the other Branch of the Medical School in Central Manchester, with an opportunity to further develop my interest in Occupational Rehabilitation. In truth, the original 1984 biopsychosocial model [1] might more properly be termed a "biopsychological model" since we had not yet been able to clarify the social part of the model, except perhaps in the trivial senses of Fordyce's recognition of pain behavior as a social event; the recognition clinically of the importance of significant others; and the importance of communication (obviously a social event).

However, since the early 1980s, the societal burden of low back disability (in terms of work loss and treatment costs) had become increasingly apparent. This was highlighted by Alf Nachemson (orthopaedic surgeon) in Gothenburg, Sweden, as the Founding Editor of the journal Spine with a group of colleagues in the International Society for the Study of the Lumbar Spine (ISSLS). These included Margareta Nordin (physical therapist), Stan Bigos (orthopaedic surgeon) and $\mathrm{GW}$ ) who targeted health and social policy in the management of back pain. Several of us developed The Back Book [16] first published in 1996 and still in wide circulation. Arguably the major LBP-related event of the decade was the publication of GW's The Back Pain Revolution [17], which not only established LBP as a biopsychosocial phenomenon, but recommended a change in the routine management of uncomplicated LBP from rest and opioids to re-activation. (His further aspiration of removing most LBP from the clutches of clinicians was not quite so successful).

The epidemiology and natural history of LBP was becoming increasingly available and methodological sophistication became a hallmark of the Low Back Forum (now the International Forum for Back \& Neck Pain Research in Primary Care, an international group of clinicians and researchers), which first met in Seattle in 1995 and has continued to meet every 12-18 months. Recently the group developed the 2019 landmark series on LBP in the Lancet [18].

Meanwhile, in New Zealand in the 1990s, the rising cost of disability claims for LBP had risen to $14 \%$ of the budget of the Accident and Compensation Corporation (ACC). If unchecked, the costs were in danger of bankrupting the ACC and in 1996, they asked Nicholas Kendall (psychologist) of the University of Otago at Christchurch to try to help. $\mathrm{He}$ recommended a narrative review of the research on secondary prevention for LBP and approached Steven Linton (psychologist) from Sweden and me to help. The ensuing Yellow Flags monograph [5] comprised a risk screening questionnaire, a structured assessment to identify any potentially problematic areas, and a set of LBP acute management guidelines. It was directed mainly at psychological predictors of chronicity and the assessment was intended to be conducted by the claims assessor soon after the initial injury claim. The objective has similarity to the approaches used in much later studies (outlined below).

\section{Occupational Perspectives}

In the 1997 Yellow Flags monograph, although the risk factors were predominantly clinical, there was also mention of work. However, clinical and occupational factors have different implications for action and may involve quite different personnel. In fact, Kim Burton (KB, osteopath \& biomechanist) and I had jointly supervised two $\mathrm{PhD}$ students focused on the LBP/workplace interface, with development of the Back Beliefs Questionnaire (BBQ) [19], an educational booklet [20], and a study of occupational screening [21]. KB and I decided that a distinction needed to be made between clinical yellow flags that focused primarily of the clinical aspects of LBP [22], perceptions of work (termed blue flags) [23] and organisational/ system variables beyond the individual's control (termed black flags). From the late 1990s onwards there have been a number of publications emanating from the flags framework, culminating in the Decade of the Flags Conference which we hosted at Keele University in 2007, and a monograph on managing flags in situ [24]. Probably the most influential outcomes, however, have been the two special series in the Journal of Occupational Rehabilitation, based on Conferences generously supported by Liberty Mutual in Hopkinton, USA. They were hosted by Glen Pransky (occupational physician) and William (Bill) Shaw) (psychologist). The issues were focused on Improving Return to Work Research (2005) [25] and on Employer Practices to Prevent Disability (2015) [26].

There are other initiatives in the 19090s that perhaps merit mention. In the U.K. there had been a progressive shift in health care policy designed to tackle the growing number of people out of work with chronic LBP. The UK Government Department For Work and Pensions (DWP) had commissioned a series of evidence-based monographs, including one on occupational screening [27] and another on the impact of work on health [28] in which GW and KB "repositioned" the workplace potentially as a source of wellbeing rather than one of stress and danger. Next, in a collaboration between The Welsh Pain Society, the Welsh Government and the DWP, Ceri Phillips (health economist) of the University of Swansea and I jointly hosted a conference targeting healthcare professionals employers and policy makers. We then set up studies of the healthcare-work interface in a Welsh mining community (Merthyr Tydfil) and produced the Wales Health and Work Report [29] and a series of publications on the health/work interface. Also, during this time, PW and I piloted occupationally oriented pain management for clients with LBP attending job centres, initially in Salford, and subsequently also with colleagues in Bristol, [4]. 


\section{Move to the University of Keele Primary Care Centre}

At the invitation of Prof. Peter Croft (primary care physician \& epidemiologist) and founder of the Primary Care Centre, I moved to Keele University. This was initially part-time from 2002-2004 and then full-time from 2004 onwards. Although my research into occupation from a primary care perspective continued, my main responsibility was to assist the development of psychologically oriented secondary prevention; focusing initially on primary care consulters with LBP. This was, in essence, resizing and reshaping the tertiary PMP we had developed in the Manchester \& Salford Pain Centre. Following an initial feasibility trial [30] we developed a training programmes which underpinned the subsequent LBP randomized controlled trials (RCT). Over a number of years inter alia we developed the Keele STarT Back Screening Tool [6], conducted a RCT of physiotherapy-led LBP (the STarT Back trial) [7]; a further implementation study [31] and evaluation of psychometric instruments [32], but undoubtedly, the most influential of these Keele studies has been the STarT Back trial in which we demonstrated the superiority (both clinically and economically) of the stratified approach to pain management. The approach features in the National Health Service England Low back and Radicular pathway of care [33] and is endorsed by the National Institute for Health and Care Excellence (NICE).

\section{Psychologically Informed Practice and Its Dissemination}

In 2009, I was invited to join the Editorial Board of Physical Therapy. In a surprise comparable with the award of the Winston Churchill Scholarship, I was telephoned by Becky Craik (physical therapist) and Dan Riddle (physical therapist), who were Editor and Deputy Editor respectively of Physical Therapy, to join the editorial board of the journal. I was highly flattered and delighted, if a bit puzzled, but naturally I agreed. Over the ensuing decade I have hugely enjoyed the experience and learnt a massive amount, not only in reviewing manuscripts but in learning from the distinguished board members, mainly physiotherapists, who shared expertise in clinical management, implementation of research and methodology. Steven George (now at Duke University) (physical therapist) and I persuaded the Editor to consider a proposal for a special issue on what we eventually termed Psychologically Informed Practice (PiP) [34]. It allowed us to pull together and integrate a range of individual efforts which placed LBP management in a person-centred framework.

Our main intention was to distinguish PiP both from traditional biomedical care and from care of more serious mental illness. PiP relies heavily on the cognitivebehavioral approach to pain management, although with an increasing emphasis on experiential learning and communication skills. However, while it is possible to declare some guiding principles and ways of doing business, context is all-important not only in the management of disability but in the assessment of pain [35] and its impact.

PiP is based on a normal psychology of people's beliefs, expectations, emotional responses and coping strategies. It seeks to lessen the grip of psychopathology \& mental illness as the default perspective on anything psychological. I understand that the special issue has been well received and think that it has kickstarted a reappraisal of pain management. In suggesting a new approach to clinical management, the 2011 special issue of PTJ offered a launch pad for Psychologically Informed Practice (PiP) as we termed the new approach. I should mention that although generally clinically focused, the issue contained a manuscript [36] on the management of occupational issues in clinical practice.

A word of caution, however. PiP is not a magic solution. It is essentially a synthesis and refocusing of previous work (primarily in the field of pain management), although innovative perhaps in the extent of its focus on communication. It is being implemented in all sorts of ways in different contexts. That is as it should be. Steven Linton has developed a psychosocial screening tool (The Orebro Musculoskeletal Pain Questionnaire or OMSPQ) and a short form [37]. At the time of writing (June 2020) a study of screening using the OMSPQ-SF is underway at MedRisk. The questionnaire was also included in an Australian study of targeted screening in hospital workers [38], one of a series of studies led by Michael Nicholas, a long term colleague and friend at the University of Sydney.

Although a number of specific techniques and procedures are at the heart of PiP [39], specific applications will vary in their "dose" and intensity. It is important however that whenever possible we aspire to an evidence-based understanding grounded on careful evaluation, informing intervention with focused implementation.

\section{Concluding Reflections}

Autobiography is prone to the bias of selective memory and sprinkled with self-delusion; but it seems to me that a huge proportion of my professional life, one way or another, has been wrestling with the subject of back pain, not because I 
am a chronic back pain sufferer (although I have had significant spells of it) but because it commands attention, it poses a challenge and it is endlessly fascinating. The backpain landscape has changed dramatically over the last four decades.

\section{What then of the Future of LBP, Its Effects and Its Management?}

There have been significant biomedical advances in all aspects of medicine, biomechanics, ergonomics and occupational medicine/rehabilitation, and we may find better non-dangerous ways of treating pain. Traumatic injury, spinal deformity and possible neoplastic disease always merit biomedical attention and advances in genetics may identify those at risk of future physical abnormalities and enable prevention.

However, most non-specific LBP will resolve or become troublesome only intermittently without treatment. We are over-treating patients and must take some responsibility as healthcare professionals for the chronic pain crisis. We need to reconsider the nature of spinal care [40] and meet the challenges of opioid addiction [41] and failed surgery [42] in particular. Indeed, there has been a plea for fundamental change globally in LBP management, at a system and health policy level, in healthcare delivery with the implementation of cost-effective strategies that provide access to effective care ensure early identification and adequate education of patients with low back pain at risk for persistence of pain and disability [43]. This will require not only tackling vested interests in retaining the status quo, but training of healthcare professionals in facilitating effective behaviour change and incentivising patients to re-engage in work.

The biopsychosocial framework has offered a new perspective on the nature of illness and led us to re-examine the relationship between mind and body and promoted the focus on how we react to pain, whether individually or as a society. The concept of pain behavior, pioneered by Fordyce, has been important in the development of specific behavioural and cognitive pain coping strategies, but when embedded within the concept of guided self-management, it offers way of addressing a way of identifying and addressing the obstacles to re-engagement in valued activity.

There are however cultural difficulties/impediments to optimising LBP management. In the USA and elsewhere, citizens appear to be paying a heavy price for the right to choose and "doctor-shop": opioid toxicity and failed surgery. If inappropriate and harmful treatment continues to be sanctioned by treatment payers, the status quo is likely to be preserved, but in some jurisdictions or systems of healthcare, it is possible to require data on treatment outcomes and develop funded evidence-based pathways, within which progress towards guided self-management can be embedded.
Indeed, it seems very probable that primary care postCoVID-19 will look rather different.

LBP has attained a particularly high profile, not only because of its prevalence but because of its impact and its cost. It will always be with us and there will always be a need to screen for potential surgical emergencies, although if based on symptoms and perhaps a video interview, this may not require an in-person consultation [40].

My main hope for further research in LBP and its management, is that we become better not only at designing but in evaluating interventions, as in making use of single case designs [44] and particularly in clarifying the role of the moderators and mediators of treatment outcome. Our focus needs to shift from the efficacy of interventions (over which we will never establish full control) to implementation, with the specification of clear outcomes, and the identification of determinants of behaviour change [45]. Wherever possible we should facilitate guided self-management in tackling behaviour change.

Recent PiP focussed conferences at the North American Spine Society in 2016 and 2019, offer encouragement of a change in how LBP is viewed in spinal care and invite further consideration of ways in which PiP training might be rolled out. The current COVID-19 crisis (as of June 2020) with its impact on healthcare delivery may provide the impetus to reconsider the nature of the relationship between HCPs and patients, with a focus on the strategies required to facilitate guided self-management and a re-engagement with necessary communication skills required, and the process of re-integration into the workplace [46]

In conclusion, the treatment and management of LBP have come a long way since the mid-70's. It seems that the case no longer needs to be made for looking at LBP in its context. We have made progress in the epidemiology and key influences on chronic pain and its effects, which principally reflect normal psychological processes rather than psychopathology or mental illness. We now understand that in addressing reactivation and re-engagement in work or social participation after injury or illness, we need to focus on behaviour change and tackle its determinants. We have made progress in identifying risk factors and targeting our interventions accordingly. In so doing, we are developing new approaches to consultation and training in their implementation. We are designing and developing interventions based on the recognition that chronic pain is complex and needs to be understood within a biopsychosocial framework. We now have an evidence-based alternative to opioid overprescription, ineffective modality treatment, and unnecessary surgery. But these new approaches require different approaches to training health care providers and much more research is needed into the influence of context on implementation. It has been a pleasure and a privilege to be part of story of LBP and its management. 
Acknowledgements I have been indeed fortunate to have had the opportunity to collaborate with a wonderful group of colleagues, many who have become close friends. I would like to make mention particularly of Bill Fordyce, Gordon Waddell, Chris Spanswick, Francis Keefe, Kim Burton, Nick Kendall, Paul Watson, Ceri Phillips, Peter Croft, Gail Sowden, Michael Nicholas, Steven Linton, Bill Shaw, Steven George, Johan Vlaeyen, Mandy Williams and Stephen Morley without whom my professional (and social) life would have been much diminished. However, I have greatly enjoyed also my contact with patients and in working with some wonderful students easing them into successful professional careers. I have delighted unashamedly in travelling the world (especially before 9/11 and the COVID-19 virus). Had a cure been found for back pain this would not have been possible!. I would also like to thank Doug Gross, Fergal O'Hagan, and Patricia Findley for helpful comments on earlier drafts. This is dedicated with love, to my wife Carolyn.

\section{References}

1. Waddell G, Bircher M, Finlayson D, Main CJ. Symptoms and signs: physical disease or illness behaviour? BMJ. 1984;289(6447):739-741.

2. Watson PJ, Booker CK, Main CJ, Chen ACN. Surface Electromyography in the identification of chronic low back pain patients: The development of a flexion relaxation ratio. Clin Biomech. 1997;12(3):165-171.

3. Waddell G, Newton M, Henderson I, Somerville D, Main CJ. A Fear Avoidance Beliefs Questionnaire (FABQ) and the role of fear avoidance beliefs in chronic low back pain and disability. Pain. 1993;52(2):157-168.

4. Watson P, Booker CK, Moores L, Main CJ. Returning the chronically unemployed with low back pain to employment. Eur J Pain. 2004;8(4):359-369.

5. Kendall N, Linton SL, Main CJ. Guide to assessing psychological yellow flags in acute low back pain: risk factors for long term disability and work loss. Wellington, N.Z: Accident Rehabilitation and Compensation Insurance Corporation of New Zealand and the National Health Committee; 1997.

6. Hill JC, Dunn DM, Lewis M, Mullis R, Main CJ, Foster NE, Hay EM. A primary care back pain screening tool: identifying patient subgroups for initial treatment. Arthritis Rheum. 2008;59(5):632-641.

7. Hill JC, Whitehurst DGT, Lewis M, Bryan S, Dunn KM, Foster NE, Konstantinou K, Main CJ, Mason E, Somerville S, Sowden S, Vohora K, Hay EM. Comparison of stratified primary care management for low back pain with current best practice (STarT Back): a randomised controlled trial. Lancet. 2011;378(9802):1560-1571.

8. Waddell G. Volvo award in clinical sciences: a new clinical model for the treatment of low back pain. Spine. 1987;12(7):632-644.

9. Waddell G, Main CJ, Morris EW, Venner RM, Rae PS, Sharmy $\mathrm{SH}$, Galloway H. Normality and reliability in the clinical assessment of backache. Br Med J. 1982;284(6328):1519-1531.

10. Keefe FJ, Block AR. Development of an observation method for assessing pain behavior in chronic low back pain patients. Behav Ther. 1982;13(4):363-375. https://doi.org/10.1016/S0005 -7894(82)80001-4.

11. Waddell G, McCulloch J, Kummel E, Robert Venner R. Nonorganic physical signs in low-back pain. Spine. 1980;5(2):117-125.

12. Main CJ, Waddell G. Behavioural responses to examination: a reappraisal of the interpretation of "Nonorganic Signs". Spine. 1998;23(21):2367-2371.
13. Main CJ, Spanswick CC. Pain management: an interdisciplinary approach. Edinburgh: Churchill Livingstone; 2000.

14. Main CJ, Keefe FJ, Jensen MP, Vlaeyen J, Vowles K, editors. Fordyce's behavioral methods for chronic pain and illness republished with commentaries. Philadelphia: ASP Press (Wolters Kluwer Health); 2015.

15. Parker H, Main CJ. Living with back pain. Manchester: Manchester University Press; 1990.

16. Roland M, Waddell G, Klaber-Moffett J, Burton AK, Main CJ, Cantrill E. The back book. Norwich: The Stationary Office; 1996.

17. Waddell G. The back pain revolution. Edinburgh: ChurchillLivingstone; 1998.

18. Hartvigsen M, Hancock MJ, Kongsted A, Louw Q, Ferreira ML, Genevay S, Damian Hoy D, Karppinen J, Pransky G, Sieper J, Smeets RJ, Underwood M, on behalf of the Lancet Low Back Pain Series Working Group. Low back pain 1: what low back pain is and why we need to pay attention. Lancet. 2018;391(10137):2356-2367.

19. Symonds TL, Burton AK, Tillotson KM, Main CJ. Do attitudes and beliefs influence work loss due to low back trouble?. Occup Med. 1996;46(1):25-32.

20. Symonds TL, Burton AK, Tillotson KM, Main CJ. Absence resulting from low back trouble can be reduced by psychosocial intervention at the workplace. Spine. 1995;20(24):2738-2745.

21. Bartys S, Burton AK, Main CJ. A prospective study of psychosocial risk factors and absence due to musculoskeletal disorders- implications for occupational screening. Occup Med. 2005;55(5):375-379.

22. Nicholas MK, Watson PJ, Linton SJ, Main CJ. The identification and management of psychosocial risk factors (Yellow Flags) in patients with low back pain. Phys Ther. 2011;91(5):737-753.

23. Shaw WS, van der Windt DA, Main CJ, Loisel P, Linton SJ. Early patient screening and intervention to address individual level occupational factors ("Blue Flags"') in back disability. J Occup Rehabil. 2009;19(1):64-80.

24. Kendall NAS, Burton AK, Main CJ, Watson PJ. Tackling musculoskeletal problems. The psychosocial flags framework: a guide for clinic and workplace. London: The Stationary Office; 2009.

25. Linton SJ, Gross D, Schultz IZ, Main CJ, Cote P, Pransky G, et al. Prognosis and identification of workers risking disability: research issues and directions for future research. J Occup Rehabil. 2005;15(4):459-474.

26. Main CJ, Shaw WS. Employer policies and practices to manage and prevent disability: conclusion to the special issue. J Occup Rehabil. 2016;26(4):490-498.

27. Waddell G, Burton AK, Main CJ. Screening of DWP clients for risk of long-term incapacity: a conceptual and scientific review. London: Royal Society of Medicine Monograph; Royal Society of Medicine Press; 2003.

28. Waddell G, Burton AK. Is work good for your health and wellbeing. London: TSO; 2003.

29. Main CJ, Phillips CJ, Thomas AP, Farrell A. The Wales Health Work Report. Welsh Assembly Government (and Dept. for Work \& pensions, UK); 2004.

30. Hay E, Mullis R, Lewis M, Vohora K, Main C, Watson PJ, Dziedzic K, Sim J, Minns-Lowe C, Croft P. Comparison of physical treatments versus a brief pain management programme for back pain in primary care: a randomised clinical trial in physiotherapy practice. Lancet. 2005;365(9476):2024-2029.

31. Foster NE, Mullis M, Hill JC, Lewis M, Whitehurst DGT, Doyle C, Konstantiniou K, Main CJ, Somerville S, Sowden G, Wathall S, Young J. Hay EM Effect of stratified-care for low back pain in general practice (IMPaCT Back): a prospective population-based sequential comparison. Ann Fam Med. 2014;12(2):102-111. 
32. Foster NE, Thomas E, Bishop A, Dunn K, Main CJ. Distinctiveness of psychological obstacles to recovery in low back pain patients in primary care. Pain. 2010;148(3):398-440.

33. Case study. Implementing stratified care for low back pain: STarT Back. Public Health England: www.Gov.UK; 2017.

34. Main CJ, George SZ. Psychologically Informed Practice for management of low back pain: future directions in practice and research. Phys Ther. 2011;91(5):820-827.

35. Main CJ. PAIN CLASSICS: Special review. Pain assessment in context: a state of the science review of the McGill Pain Questionnaire 40 years on. Pain. 2016;157(7):1387-1399.

36. Shaw WS, Main CJ, Johnson V. Addressing occupational factors in the management of low back pain: implications for physical therapist practice. Phys Ther. 2011;91(5):777-789.

37. Linton SJ, Nicholas MK, MacDonald S. Development of a short form of the Örebro Musculoskeletal Pain Screening Questionnaire. Spine. 2011;36(22):1891-1895.

38. Nicholas MK, Costa DSJ, Linton SJ, Main CJ, Shaw WS, Pearce G, Gleeson M, Pinto RZ, Blyth FM, McCauley JH, Smeets McGarity RJEMA. Implementation of early intervention protocol in Australia for 'high risk' injured workers is associated with fewer lost work days over 2 years than usual (stepped) care. J Occup Rehabil. 2019;29(2):295-302.

39. Keefe FJ, Main CJ, George SZ. Advancing Psychologically Informed Practice (PiP) for patients with persistent musculoskeletal pain: promise, pitfalls and solutions. Phys Ther. 2018;98(5):398-407.

40. Main CJ, Wetzel FT. Editorial: Psychologically informed Practice (PiP): a brief review and proposal for integration in a changing healthcare model Spineline 2020; May-June.
41. Reardon S. US health agency pours $\$ 350$ million into the fight against the opioid crisis. Nature. 2019. https://doi.org/10.1038/ d41586-019-288-2.

42. Inoue $\mathrm{S}$, Kamiya M, Nishihara M, Arai YP, Ikemoto T, Ushida T. Prevalence, characteristics, and burden of failed back surgery syndrome: the influence of various residual symptoms on patient satisfaction and quality of life as assessed by a nationwide internet survey in Japan. J Pain Res. 2017;10:811-823. https://doi. org/10.2147/JPR.S129295.

43. Buchbinder R, van Tulder M, Öberg Costa BLM, Woolf A, Schoene M, Croft P, on behalf of the Lancet Low Back Pain Series Working Group. Low back pain: a call for action. Lancet. 2018;391(10137):2384-2388.

44. Morley SJ (2018) Single case methods in clinical psychology: a practical guide. In: Masterton CS, Main CJ, editors. Abingdon, Routledge.

45. Michie S, Johnston J, Francis J, Hardeman W, Eccles M. From theory to intervention: mapping theoretically derived behavioural determinants to behaviour change techniques. Appl Psychol. 2009;57(4):660-680.

46. Shaw WS, Main CJ, Findley PA, Collie A, Kristman VL, Gross DP. Opening the workplace after COVID-19: what lessons can be learned from return-to-work research? J Occup Rehabil. 2020; https://doi.org/10.1007/s10926-020-09908-9.

Publisher's Note Springer Nature remains neutral with regard to jurisdictional claims in published maps and institutional affiliations. 